\title{
MERKEL CELL CARCINOMA
}

\section{Krzysztof Nocoń}

MD Department of General, Endocrinology and Oncology Surgery,

Multidisciplinary Hospital, Jaworzno,

e-mail: Knocon@op.pl, orcid.org/0000-0001-7182-7580, Poland

\section{Jakub Majewski}

MD, Department of General, Endocrinology and Oncology Surgery,

Multidisciplinary Hospital, Jaworzno,

e-mail: Kubamaj@gmail.com, orcid.org/0000-0003-1576-3193, Poland

\section{Józef Kurek}

MD, PhD, Head of Department of General, Endocrinology and Oncology Surgery,

Multidisciplinary Hospital, Jaworzno,

e-mail: Jkurek@gmail.com, orcid.org/0000-0002-0589-7254, Poland

\section{Goran Stojiljković}

Prof. dr, Faculty of Medicine, University of Novi Sad,

e-mail: goran.stojiljkovic@mf.uns.ac.rs, orcid.org/0000-0002-5675-2418, Serbia

\section{Antoni Stadnicki}

Profesor, MD, PhD, DSc, Polonia Academy in Częstochowa, Multidisciplinary Hospital, Jaworzno, e-mail: astadnic@wp.pl , orcid.org/0000-0003-2675-3732, Poland

Abstract. In XXI century Merkel cell carcinoma (MCC) is a still very rare form of the skin cancer with an aggressive behavior. We present a case of 77-year-old female patient with a tumor with bluish skin, approx. $2 \mathrm{~cm}$ diameter, hard texture palpation of the right zygomatic area of the face. There were no enlarged lymph nodes in the head or neck. Tumor was surgically excised. The result of the histopathological examination including immunohistochemical tests allowed to diagnose Merkel cell carcinoma. After 6 months tumor recurrence was found. The right cheek tumor and the right lymphatic system of the neck was removed and radiotherapy was carried out. In imaging examination no pathological changes were found. The patient have complained about dry eye syndrome as side effect o treatment. A literature review concerning risk factors, diagnostic difficulties, classification and treatment of Merkel cell carcinoma is presented and discussed. Randomized studies are required to clarify diagnostic procedures, prognostic factors and treatment in clinical stages of the disease

Keywords: Merkel cell carcinoma, MMC, diagnosis, treatment, radiotherapy, classification.

DOI: http://dx.doi.org/10.23856/3614

\section{Introduction}

Merkel cell carcinoma (MCC) is a rare skin cancer of high malignancy derived from neuroendocrine cells (Merkel cells). It was first described in 1972 (15) and its current name has been used since 1982, but some authors use the name- neuroendocrine skin cancer (10). In physiology Merkel cells are located in the basal layer of the epidermis and act as touch receptors; they receive sensory stimuli. Cyril Toker in 1972 year published an electron 
microscope study describing previously unknown neurosecretory granules in skin trabecular carcinoma cells, which changed the view of researchers on its histogenesis $(13,15,17)$, as well as allowed to learn about the morphology of the tumor. The incidence of Merkel cell carcinoma is low. In Western countries it is estimated to be between 0.25 and 0.32 / 100,000 per year. The main risk factors for Merkel cells cancer include exposition to ultraviolet rays, immunosuppressive treatment, HIV infection, older age, and those having frequent contact with arsenic. There has also been a higher incidence of Merkel cancer with other cancer e.g. breast cancer, ovarian cancer, Hodgkin's disease, B-cell lymphomas, chronic lymphocytic leukemia, larynx cancer $(10,11)$. There have been few reports in the literature linking the etiopathogenesis of Merkel cell carcinoma with the MCV virus (Merkel cell polyomavirus $-\mathrm{MCPyV}$ or MCV) (3).

\section{Case report}

A seventy-seven-year-old female patient was admitted to the Department of General, Endocrinology and Oncology Surgery, Multidisciplinary Hospital in Jaworzno with a tumor of the right zygomatic area of the face lasted for 6 months. For last 2 months the tumor has grown mostly. In the physical examination intradermal nodule with bluish skin, approx. $2 \mathrm{~cm}$ diameter, hard texture palpation, painless was found in the zygomatic right area. There were no enlarged lymph nodes in the head or neck. $X$ ray of the chest was performed without any pathological changes except for scoliosis of the thoracic spine. After performing standard bood preoperative tests and ECG, the patient was operated under local anesthesia. The resected tumor was sent for histopathological examination. The patient was discharged home after 2 days in good condition, with a properly healing wound. The histopathological examination revealed; neoplasma malignum male differentiatum microcellulare, CK (-), CD45 (-), Ki67 about 50\%, Chrom A (- / +), suspected Merkel cell carcinoma. The patient was admitted to the Oncology Institute in Gliwice, where histopathological examination was verified, including immunohistochemical (IHC) tests. The result of the examination at the Oncology Institute was as follows: the morphological picture in correlation with the result of the IHC study was: Merkell Cell Carcinoma, neoplasmatic tissue present in the margin; CHR (+), CK7 (+), CK 20 (+), LCA (-), TTF (-). It was recommended to next surgery - wide scar removal. The patient was reoperated in the Department of Surgery in Jaworzno, the scar was removed under local anesteshia. Histopathological examination - Merkel carcinoma removed with a margin $>0.3 \mathrm{~cm}$. The patient with the above result reported again to the Oncology Center in Gliwice. Since then, the patient has been under the care in Oncology Center, Gliwice.

After approximately 7 months tumor recurrence was found. The patient was qualified for the second stage treatment - tumor resection and adjuvant radiotherapy. The right cheek tumor and the right lymphatic system of the neck was removed (floor I-IV). In the second stage the area at right cheek was reconstructed using the free frontal - lateral flap of the left thigh. Complementary radiotherapy was carried out in 30 cycles at a dose of up to 60Gy. In addition imaging examination; computer tomography (CT) of the head and neck and then MR of the head was performed. No pathological changes were found. Moreover the right cheek lobe reconstruction has been corrected. In addition lesion was recognized and excised from the left cheek mucosa. Bowen's disease (lesion) was diagnosed in histopathological examination. The place in left check after excision underwent brachytherapy (46 Gy dose). In the netx imaging examination $\mathrm{CT}$ of the head performed, no pathological changes were found. 
The patient have complained about dry eye syndrome, connected with drawing the lower eye lid down through a scar after surgery. Patient was under constant control at the Oncology Center in Gliwice.

\section{Discussion}

Due to the rarity of Merkel cell carcinoma, its nonspecific appearance as well as the slow growth, diagnosis and confirmation occur after surgical resection and histopathological examination. The possibility of material evaluation using an electron microscopy and of immunohistochemical tests facilitates diagnosis. A similar diagnostic procedures was applied in our case. The most important adverse prognostic factors include male gender, age over 65 years, tumor location on the limbs, tumor size $>2 \mathrm{~cm}$, lymph node status - stage N1, previous immunosuppressive treatment $(2,4,7,16)$, and previous radiation treatment. The average age of diagnosis is around 70 years (7). It should be noted that lesion after radiation with local vessel damage makes it difficult resects a with a wide oncological margin.

Literature review indicates that the majority of Merkel cancer cases were restricted to skin $-66 \%$, and in $27 \%$ lymph nodes are additionally affected. The lesion is located mainly on head or neck (49\%), on limbs $(45 \%)$ and on the thorax $(15 \%)$, thus to places exposed to solar radiation (2). In our patient, the location of the Merkel cancer concerned precisely to place exposed to solar radiation. However, Merkel's cells cancer may be located in mucous membrane of mouth, nose, genitals, mostly yet unknown etiopathological factors (16).

It is believed that at the time of diagnosis $50 \%$ of patients have metastatic lymph nodes and in $35 \%$ distant metastases are present. $(14,17)$. In our patient there were no metastatic lesions in lymph nodes and other metastasis. The 5-year survival rate if the disease only affects the skin - is $56-60 \%$, and drastically decreases to $0-18 \%$ in patients with lymph node, central nervous system or lung involvement. (18). Lemos et al. (7) based on an analysis of 5823 cases of the Merkel's cancer in American Medical Databases proposed a 4-stage classification system, which was adopted by the American Joint Committee on Cancer.

The current, slightly modified system divides Merkel cell carcinoma into the following stages:

I. grade I - the disease is limited to the skin and its size $\leq 2 \mathrm{~cm}$

- for subcategory A - no metastases in regional lymph nodes was confirmed by histological examination of dissected nodes

- subcategory B - no metastases in lymph nodes based only on clinical evaluation.

II. grade II - the disease is limited to the skin and its size $>2 \mathrm{~cm}$

- for subcategory A - no metastases in regional lymph nodes was confirmed by histological examination of dissected nodes

- subcategory B - no metastases in lymph nodes based only on clinical evaluation

- subcategory C - primary tumor infiltrates tissues other than skin (T4) and at the same time there is no metastasis in regional lymph nodes (regardless of the method of assessment of the nodes).

III. grade III in which the lesion additionally involves regional lymph nodes

- subcategory A - metastases in regional lymph nodes confirmed by histopathology, but not clinically confirmed

- subcategory B - metastases in regional lymph nodes confirmed by clinical examination.

IV. grade IV - distant metastases are found .

Merkel cell carcinoma usually has the form of a fairly fast-growing tumor or hard skin 
infiltration, often with red purple. Ulceration is rare. Sometimes the tumor spreads through local lymph vessels, which leads to the formation of satellite foci. Diagnosis of a suspected Merkel cell cancer and assessment of its stage is difficult. Investigators have indicated diagnostic procedures as biopsy of the lesion with histopathological examination, which must be supplemented with immunohistochemical tests (4). Pre-operative thin needle biopsy of lymph nodes is also recommended for all patients with Merkel cell cancer to maximize test accuracy $(5,9)$. Additional examinations include ultrasonography of the lymphatic nodule and its absorbent lymphatic flow. CT or magnetic resonance (MR) or nuclear lymphoscintigraphy, intraoperative sentinel node biopsy (5), and positron emission tomography (PET) $(6,12)$.

CT and PET are also effective in detecting bone metastases, which should always be supplemented with a fine needle biopsy of suspicious lesions to confirm metastases (6). In the group tested by the National Comprehensive Cancer Network (NCCN) without adenopathy but with a positive needle biopsy in $14 \%$ of patients PET confirmed lymph node metastasis(12). NCCN recommendations for the treatment of Merkel's cancer suggest a multidisciplinary approach $(8,12)$. Despite the fact that Merkel cell carcinoma, as lowdifferentiated, is sensitive to chemotherapy and radiation. The basic method of treatment is surgical resection with microscopic assessment of the radicality of the procedure. If the cancer has a higher recurrence rate, adjuvant radiotherapy is commonly recommended. $(10,14,17)$. A similar therapeutic procedure was adopted in our patient.

Cancer therapy in stage I should be excision of the lesion with safe $-2-3 \mathrm{~cm}$ margin of resection. $(1,10,17)$. If the excision of the lesion with a $1-2 \mathrm{~cm}$ or less margin was performed e.g in face, it must be supplemented with postoperative radiotherapy of the tumor area and local lymphatic drainage $(10,17)$. Such recommendation correspond to treatment of our case. Local recurrence was found to be about twice as common when Merkel cell carcinoma if excised with a margin less than $2,5 \mathrm{~cm}$. $(10,17)$ Adjuvant radiotherapy should be performed as soon as possible, which significantly improves the prognosis. The authors report on the longer life span of patients who have undergone radiation therapy $(5,9)$. A similar problem occurred in our patient - the margin was less than $1 \mathrm{~cm}$, thus postoperative radiotherapy was performed. Local or regional recurrence after surgical treatment only, occurs in approximately $39 \%$ and $46 \%$ of patients, respectively, and decreases to approximately $26 \%$ and $22 \%$ respectively after adjuvant radiotherapy $(10,11,17)$. Most authors believe that chemotherapy is not necessary at the first stage of the disease $(4,12)$. In stage II, apart from tumor excision, regional lymph nodes should be removed with adjuvant radiotherapy. The dose of radiation depends on the margins of the resected tumor. If it is not possible to indicate precisely margins, in some centers chemotherapy is also used. (4). In clinical stage III, in the presence of regional lymph node metastases, lymph node resection. must be performed. Some authors postulate that chemotherapy should be considered in patients with massive lymph node involvement. (8). No typical systemic treatment in these patients is established; treatment may be as neoadjuvant or adjuvant. However, the data available in the literature do not give an unequivocal answer as to whether systemic treatment improves overall survival in this group of patients. Regarding palliative treatment in, there are no guidelines for the management of inoperable patients. There is also a lack of data of efficiency of radiotherapy and chemotherapy in this stage of the disease (11). Some authors (mainly from the USA) do not confirm the reduction in the frequency of cancer recurrence after the use of postoperative radiotherapy in such stage $(5,14)$.

In the management of primary Merkel cancer (surgical and systemic) current recommendations suggest close clinical supervision over every patient who is being treated 
for Merkel cell cancer. This supervision includes a check-up of the skin and lymph nodes every 3 to 6 months for a period of 2 years after diagnosis, and an examination every 6 to 12 months after 2 years. Recently, it has been suggested to introduce PET as a routine procedure for high-risk patients. Hawryluk et al (6) performed 33 follow-up PET examinations in patients after therapy, which in $42 \%$ of patients detected relapse and in 35\% detected at least one metastasis. These authors determined an average time to relapse of 15.3 months, $91 \%$ of relapses occurred within 2 years of diagnosis $(1,7)$.

The case of Merkel cancer presented in the article reflects diagnostic and therapeutic problems of this disease. According to American Joint Committee on Cancer our patient had early of Merkel cell cancer which usually needs surgical excision. However tumor recurrence was found, thus after next tumor excision the right lymphatic system of the neck was removed and radiotherapy was applied. Randomized studies are required to clarify diagnostic procedures, prognostic factors and treatment in clinical stages of the disease.

\section{References}

Allen, P. J., Bowne, W. B., Jaques, D. P., Brennan, M. F., Busam, K., and Coit, D. G. (2005). Merkel cell carcinoma: prognosis and treatment of patients from a single institution. Journal of Clinical Oncology, 23 (10), 2300-2309. DOI: 10.1200/JCO.2005.02.329. [in English].

Buel, J. F., Trofe, J., Hanaway, M. J. (2002). Immunosuppression and Merkel cell cancer. Transplatation Proceedins, 34 (5), 1780-1781. DOI: 10.1016/S0041-1345(02)03065-8. [in English].

DeCaprio, J. A. (2017). Merkel cell polyomavirus and Merkel cell carcinoma. Philosophical Transactions of the Royal Society B: Biological Sciences, 19, 372, 20160276. DOI: 10.1098/rstb.2016.0276. [in English].

Głombiowska, M, Imko-Walczuk, B, .Jaśkiewicz, J. (2010). Rak z komórek Merkla, ze szczególnym uwzględnieniem chorych leczonych immunosupresyjnie. Nowotwory, (60) 6, 554-559. [in English].

Gupta, S. G., Wang, L. C., Peñas, P. F., et al. (2006). Sentinel lymph node biopsy for evaluation and treatment of patients with Merkel cell carcinoma: The Dana-Farber experience and meta-analysis of the literature, Arch. Dermatol.,142, 685-690. [in English].

Hawryluk, E. B., O'Regan, K. N., Sheehy, N., et al. (2013). Positron emission tomography / computed tomography imaging in Merkel cell carcinoma: a study of 270 scans in 97 patients at the Dana-Farber / Brigham and Women's Cancer Center. Journal of the American Academy of Dermatology, 68, 592-599. [in English].

Lemos, B. D., Storer, B. E., Iyer, J. G., et al. (2010). Pathologic nodal evaluation improves prognostic accuracy in Merkel cell carcinoma: analysis of 5823 cases as the basis of the first consensus staging system. Journal of the American Academy of Dermatology, 63,751-761. [in English].

Medina-Franco, H., Urist, M. M., Fiveash, J., et al. (2001). Multimodality treatment of Merkel cell carcinoma: case series and literature review of 1024 cases. Annals of Surgical Oncology, 8, 204-208. [in English].

Miller, N. J., Bhatia, S., Parvathaneni, U., et al. (2013). Emerging and mechanism-based therapies for recurrent or metastatic Merkel cell carcinoma. Current Treatment Options in Oncology, 14 (2), 249-263. DOI: 10.1007/s11864-013-0225-9. [in English].

Osuch-Wójcikiewicz, E., Bruzgielewicz, A. (2003). Rak z komórek Merkla. Magazyn Otolaryngologiczny, 2, 42 - 44. [in Polish]. 
Poulsen, M. (2004). Merkel-cell carcinoma of the skin. Lancet Oncology, 5 (10), 593-599. DOI: 10.1016/S1470-2045(04)01593-1. [in English].

Siva, S., Byrne, K., Seel, M., et al. (2013). 18F-FDG PET provides high-impact and powerful prognostic stratification in the staging of Merkel cell carcinoma: a 15-year institutional experience. Journal of Nuclear Medicine, 54, 1223-1229. [in English].

Tang, C. K., Toker, C. (1978). Trabecular carcinoma of the skin: an ultrastructural study. Cancer. 42, 2311-2321. [in English].

Thakuria M, LeBoeuf, N. R., Rabinowits, G. (2014). Update on the biology and clinical management of Merkel cell carcinoma. American Society of Clinical Oncology. Education Book 34, 405-10. DOI: 10.14694/EdBook_AM. 2014. 34. e405. [in English].

Toker, C. (1972). Trabecular carcinoma of the skin. Arch. Dermatol, 105,107-110. [in English].

Williams, R. H., Morgan, M. B., Mathieson, I. M. et al. (1998). Merkel cell carcinoma in a renal transplant patient: increased incidence? Transplantation, 65 (10), 1396-1397. DOI: 10.1097/00007890-199805270-00019. [in English].

Ziótkowska, E., Pietrusińska, E., Biedka, M. i wsp. (2008). Rak z komórek Merklaneuroendokrynny rak skóry, postępowanie. Onkologia w Praktyce Klinicznej, 4, 141-144. [in Polish]. 